\title{
National Cancer Institute
}

National Cancer Institute

\section{Source}

National Cancer Institute. National Cancer Institute. NCI Thesaurus. Code C19202.

The Federal Government's principal agency for cancer research. NCl conducts, coordinates, and funds cancer research, training, health information dissemination, and other programs with respect to the cause, diagnosis, prevention, and treatment of cancer. Part of the National Institutes of Health of the United States Department of Health and Human Services. 